\title{
Reversible Phagocytosis in Rabbit Polymorphonuclear
}

\section{Leukocytes}

\author{
R. D. Berlin, J. P. FerA, and J. R. Pfeiffer, Department of Physiology, University of \\ Connecticut Health Center, Farmington, Connecticut 06032
}

A B STRACT We have studied the fate of inert phagocytized particles in rabbit neutrophils. Neutrophils release significant quantities of preingested oil emulsion. Roughly $50 \%$ of an ingested load is released in $40 \mathrm{~min}$ at $37^{\circ} \mathrm{C}$. By electron microscopy the process of release appears to be by exocytosis: particles appear extruded through a network of processes often accompanied by membranous vesicles. Exocytosis is temperature and glucose dependent but unlike phagocytosis does not require divalent cations. From Coulter counter measurements virtually the entire cell population appears to undergo the phagocytosisexocytosis sequence. Neutrophils undergoing exocytosis remain intact as determined by direct counts, electron microscopy, and absence of lactate dehydrogenase release. Moreover, by sequentially feeding differently labeled particles, it is shown that the processes of phagocytosis and exocytosis can occur concurrently. Indeed, it is found that ingestion accelerates release. The implications of these phenomena for membrane recycling, lysosomal enzyme release, and the killing of microorganisms are briefly discussed.

\section{INTRODUCTION}

Recent studies of the fate of substances ingested by pinocytosis or phagocytosis have emphasized their complete degradation or retention within lysosomes as so-called residual bodies (1). In neutrophils and macrophages it is usually assumed that ingested particulates are sequestered until the dissolution of the cell. On the other hand, the presence of "excretory vacuoles" is well known in unicellular organisms. Exocytosis of latex beads during encystment of amoebae has been well documented, although the process appears to require many hours (2).

We report here that rabbit neutrophils can release a significant fraction of phagocytized oil emulsion. The

Received for publication 26 October 1978 and in revised form 15 February 1979. time-course of this release is similar to that of uptake. The release appears to occur by a process of reverse endocytosis (exocytosis). Cells undergoing release remain intact as determined by direct counts, absence of lactate dehydrogenase release, and electron microscopic examination. By sequentially feeding differently labeled particles, it is shown that the processes of phagocytosis and "reverse phagocytosis" can occur concurrently. Moreover, ingestion accelerates exocytosis.

\section{METHODS}

Cells. Rabbit polymorphonuclear leukocytes (PMN) ${ }^{1}$ were obtained from glycogen-induced peritoneal exudates as before (3).

Medium. The basic medium consisted of $140 \mathrm{mM} \mathrm{NaCl}$ $10 \mathrm{mM} \mathrm{KCl}, 10 \mathrm{mM}$ Hepes, $\mathrm{pH}$ 7.5. When present the medium consists of: $\mathrm{MgCl}_{2}, 2 \mathrm{mM} ; \mathrm{CaCl}_{2}, 0.01 \mathrm{mM}$; glucose, $5 \mathrm{mM}$; EDTA, $4 \mathrm{mM}$.

Phagocytosis and quantitation of particle content. Particles of paraffin oil stabilized with albumin were prepared by sonication. Some preparations were labeled with oil red $O$ (ORO) as originally described by Stossel et al. (4). In addition, for some experiments the emulsion was labeled with the fluorescent lipophilic dye, perylene. Like ORO, perylene is not removed from the emulsion by repeated washing with aqueous solvents. Cells at $10^{7} / \mathrm{ml}$ were allowed to phagocytize oil at a final concentration of $1.25 \%$ by volume. This was nonsaturating so that uptake could be made nearly linear for up to $20 \mathrm{~min}$. To quantify oil content, the cells were first centrifuged at $4^{\circ} \mathrm{C}$ for $6 \mathrm{~min}$ at $200 \mathrm{~g}$. The supernate was saved where appropriate for further analyses. The tube above the cell pellet was carefully wiped clean and the pellet extracted into water-saturated $n$-butanol. After extraction, ORO was measured spectrophotometrically at $524 \mathrm{~nm}$ and perylene by fluorescence using 436 and $474 \mathrm{~nm}$ as excitation and emission wavelengths respectively. Under the conditions employed (dilute solutions with $O R O$ of $O D \cong 0.1$ ) the relation of absorption and fluorescence to dye concentration was linear, and the two substances mixed could be measured independently. The amount of emulsion associated with the dye was calculated from a paraffin oil stock: $1 \mu l$ oil in $1 \mathrm{ml}$ butanol saturated with water corresponded to a $0.29-\mathrm{OD}$ at $524 \mathrm{~nm}$. The perylene was dissolved in oil at

\footnotetext{
${ }^{1}$ Abbreviations used in this paper: ORO, oil red $O$; PMN, rabbit polymorphonuclear leukocyte(s).
} 
$0.1 \mathrm{mM}$. The sensitivity of the detector was adjusted so that $1 \mu$ l corresponded to $0.5 \mathrm{U}$ of fluorescence intensity.

Coulter counter measurements of cell volume. A distribution of "volumes" was recorded in a pulse-height analyzer (Channelyzer). The Coulter counter (Coulter Electronics Inc., Hialeah, Fla.) was set with a $\mathrm{T}$ window of 10-100. For the Channelyzer, the base channel threshold was 10 and the window width 100 . From the recorded data a relative volume can be determined. However, the absolute volume depends on geometrical values that could change with phagocytosis or its reversal. Hence, the primary value of these data was to ascertain whether the entire population or only a subfraction was involved in the uptake and reversal phenomena. The use of the Coulter counter for assay of phagocytosis with whole yeast cell has been recently reported (5), but the volume changes obtained are complicated in the presence of particles that may be absorbed to the surface. Absorption of oil emulsion as indicated (4) was found negligible by direct light microscopic examination.

Electron microscopy. Rabbit PMN were fixed as a loose pellet in $1 \%$ glutaraldehyde in $0.1 \mathrm{M}$ sodium cacodylate, $\mathrm{pH} 7.4$, at room temperature for $1 \mathrm{~h}$, rinsed in cacodylate, and postfixed in $2 \% \mathrm{OsO}_{4}$ in cacodylate, $\mathrm{pH} 7.4$, also at room temperature, for $1 \mathrm{~h}$. The samples were dehydrated in graded ethanols and transferred through propylene oxide to Epon (Shell Chemical Co., Houston, Tex.) for embedding at $60^{\circ} \mathrm{C}$ for $2 \mathrm{~h}$. Uranyl acetate was avoided before embedding as it variably extracted cell glycogen. Thin sections (silver) were cut and picked up on 300-mesh copper grids, doubly stained with uranyl acetate and lead citrate and examined on a Philips 300 electron microscope (Philips Electronic Instruments, Inc., Mahwah, N. J.). Approximately $1 \mu \mathrm{m}$ thick sections were stained with $0.5 \%$ methylene blue, $0.5 \%$ Azure II in $0.5 \%$ borate, $\mathrm{pH} 7.4$.

Enzyme assays. Lactate dehydrogenase was measured in 0.1\% Triton (Rohm and Hass Co., Philadelphia, Pa.) extracts of cell pellets or in supernates. Samples were excited at $340 \mathrm{~nm}$ and NADH oxidation was followed by the decrease in fluorescence at $467 \mathrm{~nm}$ in the presence of excess pyruvate.

\section{RESULTS}

Phagocytosis. With $1.25 \% \mathrm{vol} / \mathrm{vol}$ emulsion in our standard medium, phagocytosis was linear for $\cong 20$ min when expressed as oil uptake per cell. It is important that the cells separated from the emulsion by centrifugation not be washed because this was found to lead to progressive losses of the number of cells pelletable. Presumably this loss results from the flotation of relatively more engorged, buoyant cells. Thus, the volume of oil ingested per $10^{7}$ cells decreases progressively with washing. To control for any noningested contaminating emulsion in the centrifuged cell pellet, the oil content of a pellet obtained immediately after mixing was determined; this amounted to $<10 \%$ of the total in all samples and was usually $<5 \%$. This value was subtracted from the total to give the net internalized oil. The amount of oil taken up during the 20 -min period of phagocytosis averaged $0.6 \mu 1 / 10^{7}$ cells but there was great variability from day-to-day $(0.31-$ $1.39 \mu \mathrm{l} / 10^{7}$ cells). The average value corresponds to $\cong 20 \%$ of the cell volume of $3.5 \mu \mathrm{l} / 10^{7}$ cells (6).

Reversal of phagocytosis. When the postphago- cytic cells are suspended in medium without calcium or magnesium at $37^{\circ} \mathrm{C}$ a progressive decrease in pelletable oil is observed. Fig. 1 shows average values \pm 2 SD of 14 experiments. The oil associated with cells is expressed as the fraction of the uptake attained in the initial 20-min period of phagocytosis. In all experiments the number of cells pelletable after the postphagocytic incubation period was determined. In experiments in which cell losses of $>10 \%$ were found, the results were discarded. Note that the loss of emulsionladen buoyant cells cannot account for the progressive loss of emulsion with time. The release of lactate dehydrogenase into the medium during the period of reversal was also negligible, accounting for an average of $3 \pm 2 \%$ ( $2 \mathrm{SE}$, seven experiments) of total cellular lactate dehydrogenase.

Factors that influence reversal. No reversal occurs at $4^{\circ} \mathrm{C}$ (five experiments). The rate of reversal is reduced $\cong 70 \%$ at room temperature (five experiments).

Unlike phagocytosis itself, reversal does not require exogenous divalent cations. After $20 \mathrm{~min}$ incubation postphagocytosis in medium containing $4 \mathrm{mM}$ EDTA, the fraction of cell-associated oil remaining was $0.59 \pm 0.076$ ( $2 \mathrm{SE}$, eight experiments). This is actually somewhat less than the fraction obtained without EDTA, (0.68; Fig. 1).

Reversal is dependent on exogenous glucose. In these experiments cells were first allowed to phagocytize in the presence of only $1 \mathrm{mM}$ glucose with the object of partially depleting endogenous glucose stores, although this was not shown directly. The cells were then pelleted and resuspended in medium containing either no or $5 \mathrm{mM}$ glucose. As shown in Fig. 2, little reversal is seen in the absence of glucose.

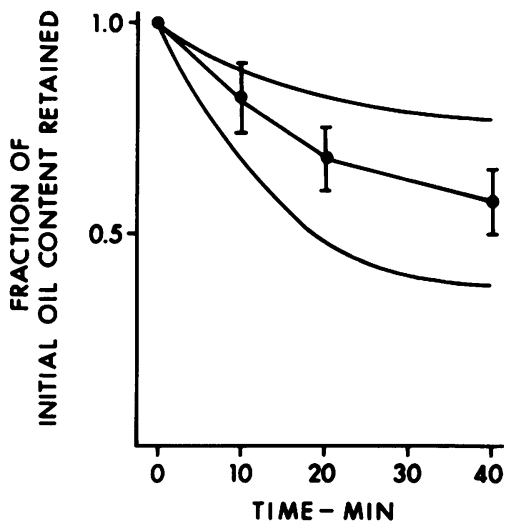

Figure 1 Residual oil content vs. time of incubation in emulsion-free medium. The data are expressed as the fraction of oil content remaining after a period of loading by phagocytosis. The latter period was $10-20 \mathrm{~min}$ and was adjusted, using direct microscopic examination, so as to prevent overengorgement and thereby flotation and loss of cells. The middle line is the average of 14 experiments, and the bars $\pm 2 \mathrm{SE}$. The outer lines show the two most extreme experiments. 


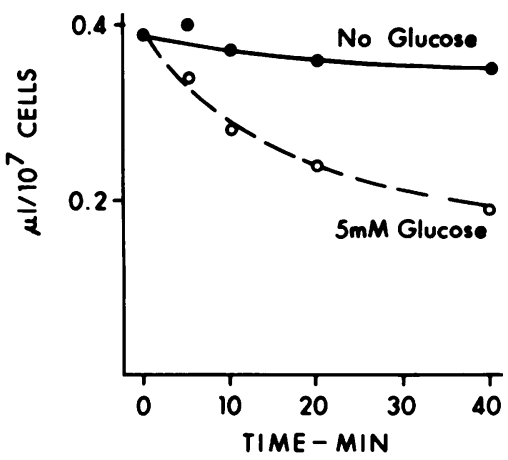

FIGURE 2 A representative experiment indicating the oil content in microliter per $10^{7}$ cells vs. time postphagocytosis in emulsion-free medium without or with $5 \mathrm{mM}$ glucose. Phagocytosis proceeded in $1 \mathrm{mM}$ glucose.

Little or no phagocytosis occurs in the presence of EDTA (7). Thus, reversal in the absence of divalent cations establishes that reversal can occur under conditions that are not compatible with phagocytosis. From the temperature and glucose dependencies it is probable that reversal is an active, energy-dependent process. In addition, these requirements establish that the decrease in oil content is not an artifact of the centrifugation procedures that are identical under all conditions.

Cell volume studies by Coulter counter. In all reversal experiments a progressive decrease in rate with time was observed. In most cases the cell content appeared to plateau. We attempted to determine if a subpopulation of cells did not undergo reversal or if reversal slowed by some other mechanism. Coulter counter analysis showed that statistically, the entire population underwent the ingestion-exocytosis sequence. Fig. 3 illustrates pulse-height distribution curves in an experiment that shows the population distribution of cell volume in control cells, its increase with phagocytosis, and its subsequent decrease after incubation (in this case with EDTA). Based on the position of the peak height and assuming similar geometric factors at all stages, the relative increase in volume after phagocytosis is $\cong 20 \%$ and this is halved after the reversal period. These changes are consistent with the volume changes predicted on the basis of measurements of cell-associated oil. More importantly, it is seen from the graph that there is a major shift in the entire distribution curve towards higher volume with phagocytosis, and lower with subsequent incubation. The distribution curve is nearly symmetric and shows no indication of bimodality. These findings indicate that the bulk of phagocytes show reversal.

Electron microscopic observations. It is well known that the resting neutrophil is highly granular and shows a subcortical region that excludes organelles (Fig. 4A). Phagocytic cells show characteristic pseudopods or

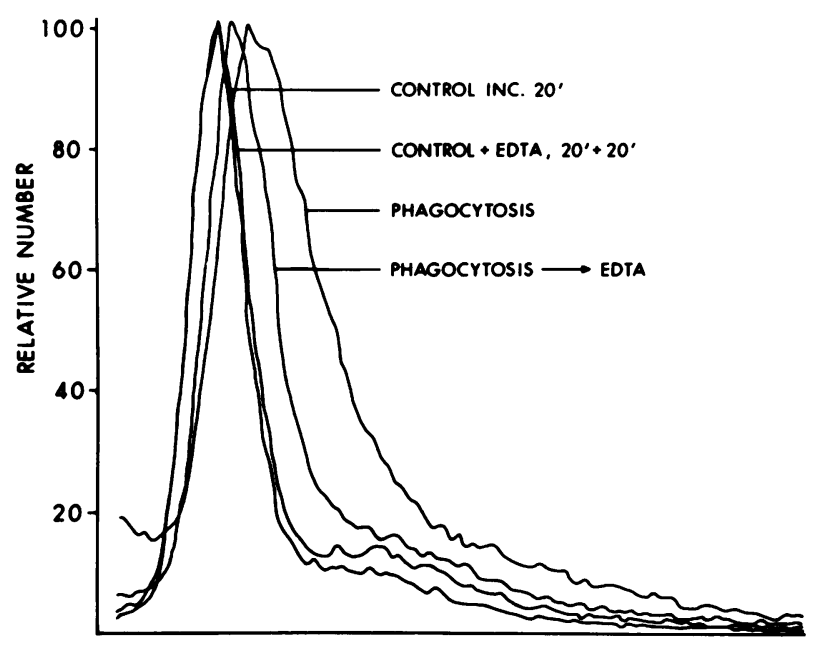

CELL VOLUME

FIGURE 3 A tracing of the Channelyzer recording of relative cell number vs. increasing cell volume. A total of 10,000 cells were counted. Cells in complete medium incubated $20 \mathrm{~min}$ in parallel with phagocytic cells are shown in the left-hand peak. After 20 min, phagocytosis the distribution is shifted significantly to the right (larger volume) in a unimodal somewhat broadened peak. On incubation for an additional 20-min period in medium with $4 \mathrm{mM}$ EDTA, control cells are unchanged in distribution. Postphagocytic cells, however, are reduced in volume toward the control, again in a relatively narrow unimodal peak. In this experiment there was no cell loss determined by direct counts under any condition.

areas surrounding the oil particles that exclude granules initially (Fig. 4B). Degranulation into phagocytic vacuoles is frequently observed. Examination of neutrophils after 20 min of phagocytosis in thick $(0.5$ $\mu \mathrm{m})$ sections, which allow distinction between intracellular and adsorbed particles, Fig. 5, reveals that essentially all cells contain some oil particles. Moreover, the bulk of ingested particles is completely internalized.

After incubation in medium without emulsion, with or without EDTA, numerous cell profiles are seen depleted of granules (Fig. 6A). Oil particles are seen being discharged into the medium. The particles are partially enveloped by granule-free cytoplasm. At what may be assumed are early stages of discharge, the cell periphery is typically broken up into thin processes as though fenestrated by numerous small perforations (6B and C). The particle is not surrounded by cell membrane. Numerous vesicular membranous structures are often attached to the cell at regions of disgorgement. These morphological observations are strikingly similar to those of Stewart and Weisman (2), who described the exocytosis of plastic beads from Acanthamoeba preceding their encystment.

Simultaneous phagocytosis and exocytosis. In Amoebae, exocytosis occurs during a period in which 

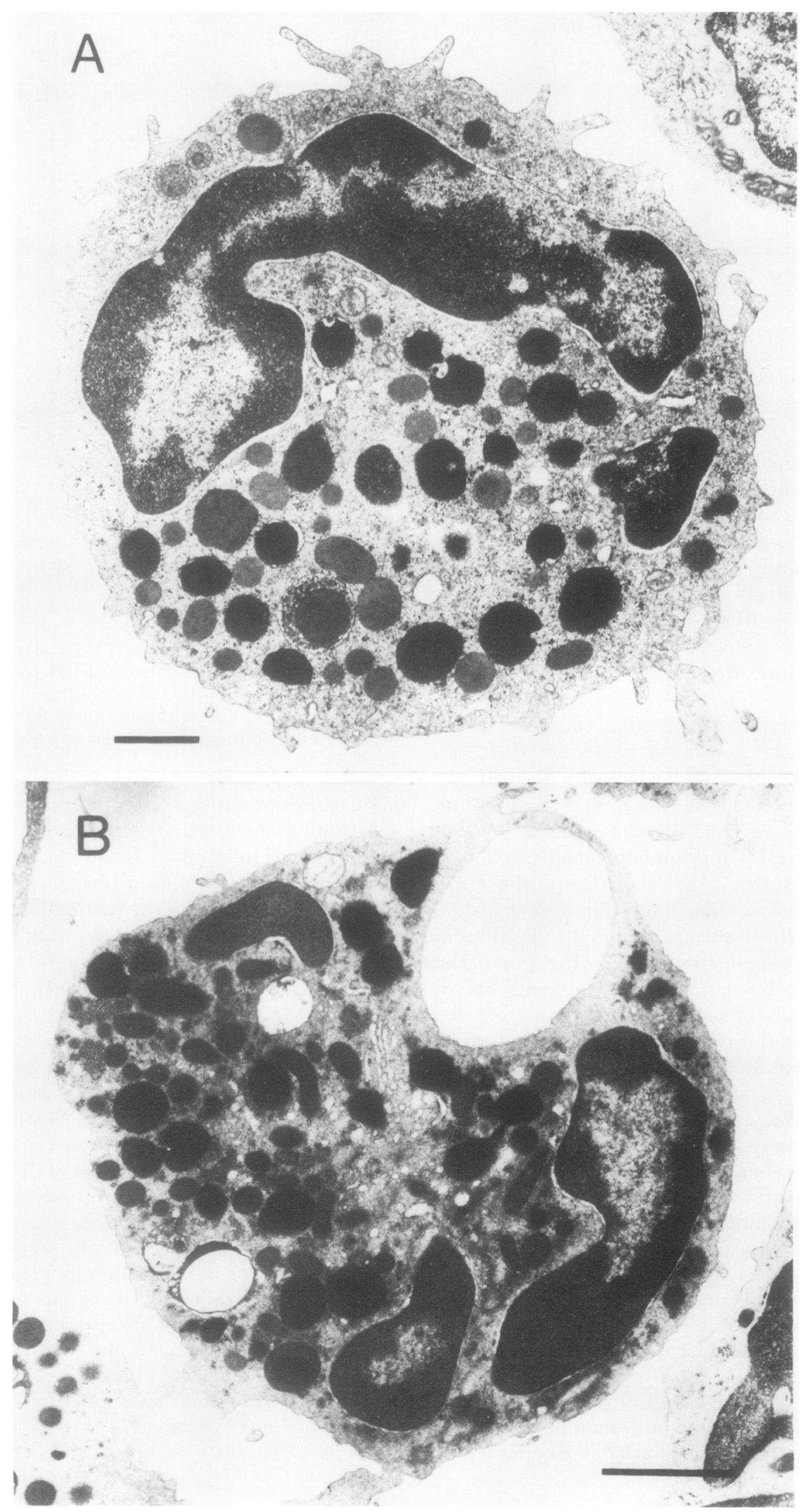
the capacity for phagocytosis is lost. We found that this is not the case for rabbit neutrophils.

In these experiments oil particles undergoing phagocytosis or exocytosis were separately identified by being labeled with either ORO or perylene. As noted, these labels could be quantified when mixed in butanol extracts. After 10 min phagocytosis of emulsion containing one label, the cells were centrifuged and allowed to phagocytize emulsion containing the second. At frequent intervals the cells were sampled for their contents of both labels. Fig. 7 shows the result of such an experiment, in which the initial phagocytosis was of perylene-labeled emulsion. It is seen that the perylene content fell $>50 \%$ in 15 min, whereas simultaneously the ORO content increased linearly. There was no cell loss during the experiment. Changing the order in which the differently labeled emulsions was given, provided essentially the same result: loss of the first label with increase of the second (five experiments). The rate of phagocytosis in the reversal period was not significantly different from that in the initial phase of phagocytosis, although uptake during the second period was usually not linear for the entire 15-min interval.

Influence of phagocytosis on exocytosis. It appeared from the preceding experiments that the rate of exocytosis was accelerated by concurrent phagocytosis. The fraction of the initial oil content remaining after 10 min was 0.82 for exocytosis in medium with EDTA and 0.56 when phagocytosis occurred simultaneously (average of four experiments). This difference was significant at the level of $P<0.001$. Because of the rapidity of this discharge and difficulties in preventing cell loss as a result of overloading of cells, we examined the course of reversal at $22^{\circ} \mathrm{C}$ with or without concurrent phagocytosis. Only experiments in which cell losses were $<10 \%$ and lactate dehydrogenase $<5 \%$ of the cell total were considered.

Cells were first loaded with ORO-labeled oil by phagocytosis at $37^{\circ} \mathrm{C}$. They were then gently centrifuged and resuspended at $22^{\circ} \mathrm{C}$ in either medium containing glucose and EDTA (usual reversal medium) or in medium containing perylene-labeled emulsion. Incubation was then allowed to proceed at $22^{\circ} \mathrm{C}$. The time-course (average of five experiments) illustrated in Fig. 8 shows clearly the acceleration of exocytosis associated with continued ingestion.

When cells are allowed to phagocytize two differently labeled emulsions sequentially then suspended in medium with EDTA and incubated, the rates of loss of the two labels are nearly identical, indicating little or no discrimination based on time of residence within the cell. It must be emphasized however that the processing of ingested particles, indicated by lysosomal fusion with the phagocytic vesicle, occurs rapidly (4).

\section{DISCUSSION}

The foregoing results establish the exocytosis of previously phagocytized particles by rabbit PMN. The extension of this phenomenon to other mammalian cell types that are involved in inflammatory and immune responses is under study.

PMN rapidly disgorge roughly $50 \%$ of an ingested load of inert particles without disruption as judged from direct counts, absence of lactate dehydrogenase excretion, and their continued capacity for phagocytosis. Reversal of phagocytosis is glucose and temperature dependent but does not require exogenous divalent cations. From pulse-height-volume analysis (Coulter counter), electron microscopy, and the extent of reversal, it is clear that the process takes place within virtually the entire PMN population (i.e., it is not a property of a subclass of cells).

It is important, we feel, that cells studied for reversal of oil particle phagocytosis not be extensively washed. Controls show that a single centrifugation and careful cleanup of emulsion adsorbed to the sides of the centrifuge tube leaves a nonphagocytized residue of no $>5-10 \%$ of the cell content of oil. Extensive washing instead simply removes an increasing fraction of the most buoyant, aggressive phagocytes. Without cell counts this phenomenon is obscured by normalizing uptake data to cell protein.

Although extensive quantitative studies of lysosomal enzyme release were not done, preliminary experiments show release of $\beta$-glucuronidase and glucosaminidase during reversal. Given the extensive fusion of lysosomes with phagocytic vacuoles containing oil particles readily observable by electron microscopy (Fig. 6B) and previously documented by biochemical analysis (8), the exocytosis of particles must inevitably lead to excretion of lysosomal enzymes. Reversal constitutes still another mode in addition to "regurgitation during feeding" and "frustrated phagocytosis" by which lysosomal enzymes may also be discharged into the extracellular space. It should be emphasized, as shown in Fig. 5, that after cell loading most particles are within the cell and cannot be simply lost through desorption during subsequent incubations. Moreover, as shown in Fig. 8, loss of previously ingested particles is accelerated during the uptake of a second particle. Thus, conditions would appear to be favorable for the

FIGURE 4 Electron micrographs $(-, 1 \mu \mathrm{m})$. (A) Control, nonphagocytizing rabbit neutrophil. Abundant granules and peripheral exclusion zone are evident. (B) Phagocytizing rabbit neutrophil. Note familiar agranular pseudopod and lysosome-phagosome fusion (arrows). 


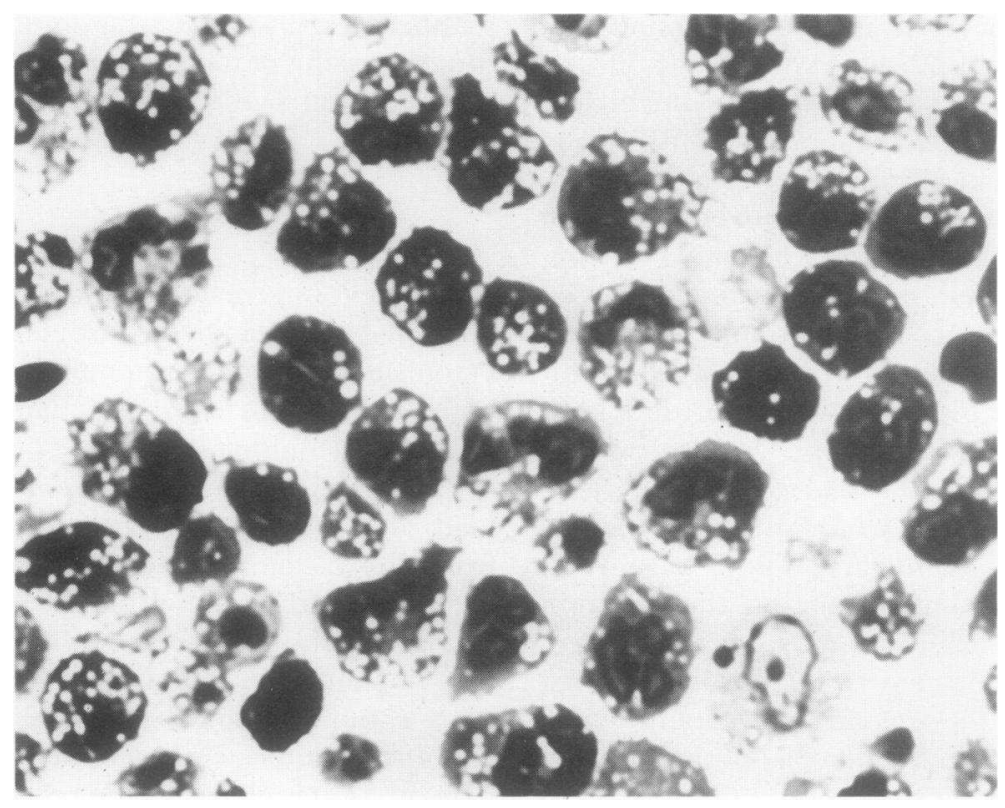

FigURE 5 A thick ( $\cong 1 \mu \mathrm{l}$ ) section of plastic embedded neutrophils after 20 min phagocytosis. The section is stained with $0.5 \%$ methylene blue, $0.5 \%$ Azur II in borate, pH 7.4 . Virtually all cells have taken up oil droplets indicated by the clear areas and most droplets are fully internalized.

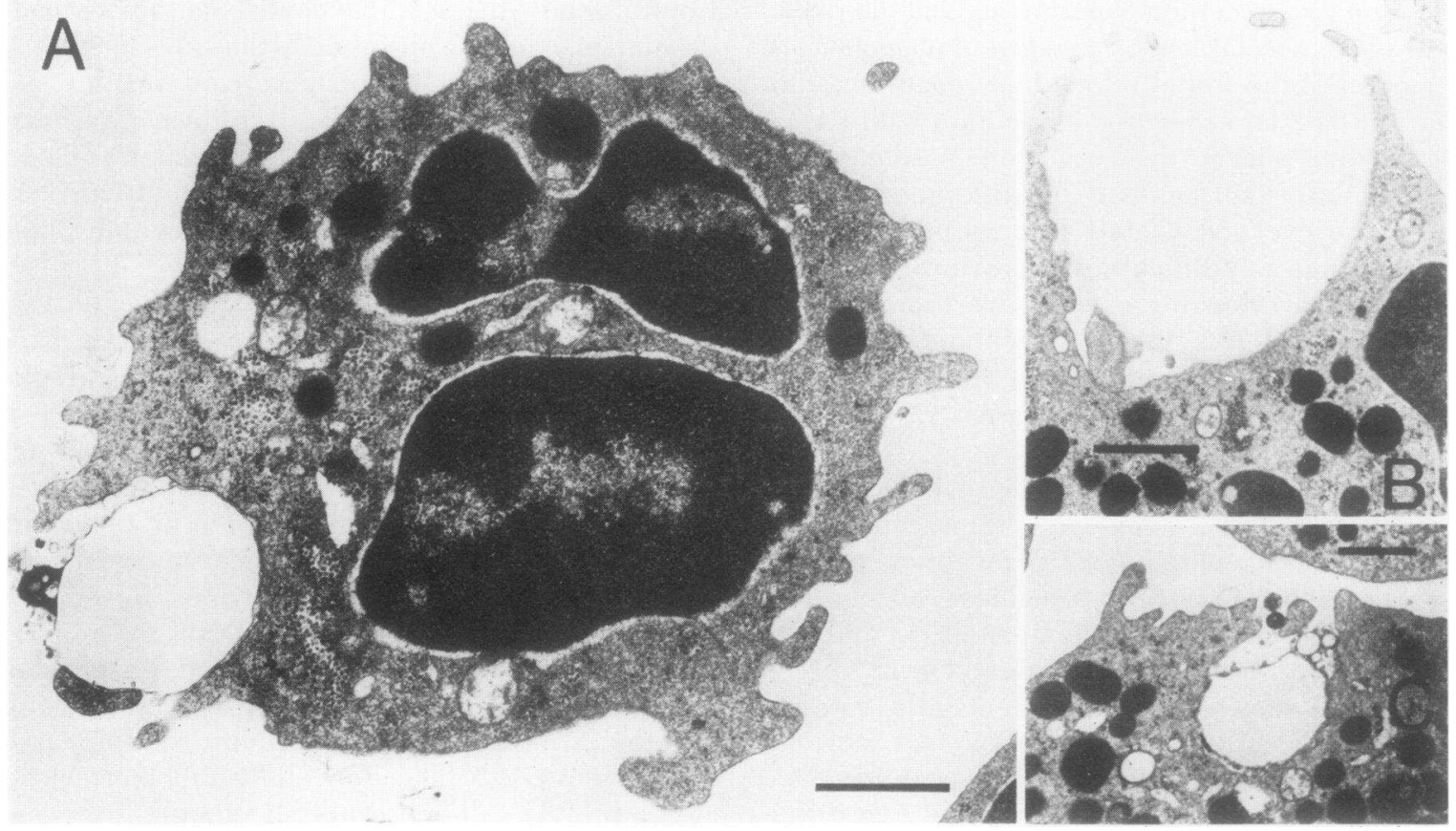

FIGURE 6 (A) Rabbit neutrophil undergoing exocytosis of previously ingested oil. Cell fixed after 20 min incubation in EDTA medium and removal of emulsion. Cytoplasm is depleted of granules (compare Fig. 4A). The overlying cell appears broken up by fenestrations and various membranous vesicles and(or) osmiophilic (lysosomal?) material is loosely associated with the particle. (B and C) The fenestrations are again visible. This is distinctly different from the pattern of ingestion (Fig. 4B) in which there are smooth pseudopodial extensions that are never interrupted except for a single region that remains unenclosed (1). Note that where the cell is not so depleted of granules, as in $4 \mathrm{~A}$, the region near the particle undergoing exocytosis is by contrast devoid of granules suggesting a filamentous network. Note also that the particle is not surrounded by cell membrane. 


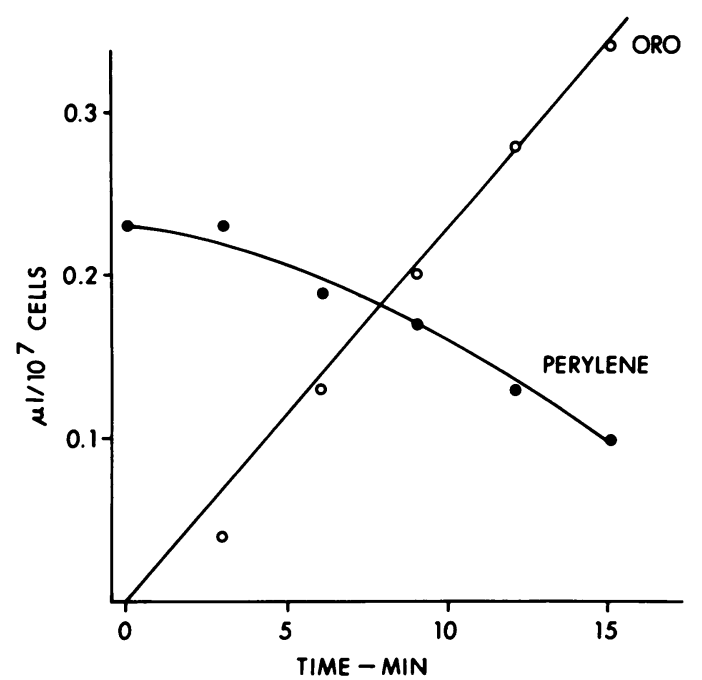

Figure 7 A plot of oil content vs. time. Cells were initially loaded by phagocytosis of perylene-labeled emulsion. They were then centrifuged, the supernate containing uningested emulsion removed, and the cells resuspended in phagocytic medium containing ORO-labeled emulsion. At intervals, aliquots were removed and the cells analyzed for their contents of perylene and ORO. It is seen that while there is a progressive increase in ORO, perylene content falls by $>50 \%$ in $15 \mathrm{~min}$.

continued internalization of any incompletely enveloped particles remaining after the first round of phagocytosis. Reversal is, therefore, most likely the consequence of some intracellular event.

The precise mechanism of exocytosis is not yet defined. The cell structure surrounding particles in process of exocytosis excludes ganules. Coupled with glucose and temperature dependencies it seems likely that a filamentous contractile system is active in expelling the particle, but this is not proven. A similar argument was advanced by Stewart and Weisman (2) to explain exocytosis of beads in Acanthamoebae. Although the population of amoebae took many hours to eliminate intracellular beads, it is possible that individual cells could undergo exocytosis at rates comparable to PMN. Again we note that in Acanthamoebae, this exocytosis occurs at a time during which phagocytosis is blocked in contrast to the PMN, in which phagocytosis and exocytosis can occur at the same time.

The possibility that membrane internalized with pinocytosis is recycled back to the plasma membrane has been inferred by Steinman et al. (9). Our studies suggest the direct reinsertion of plasma membrane components during exocytosis: the release of particles seems accompanied by fusion of the phagolysosome membrane with the plasmalemma. It seems likely that some interiorized constituents of the latter are thereby recycled. However, the presence of what appears to be shed membranous material near the site of particle

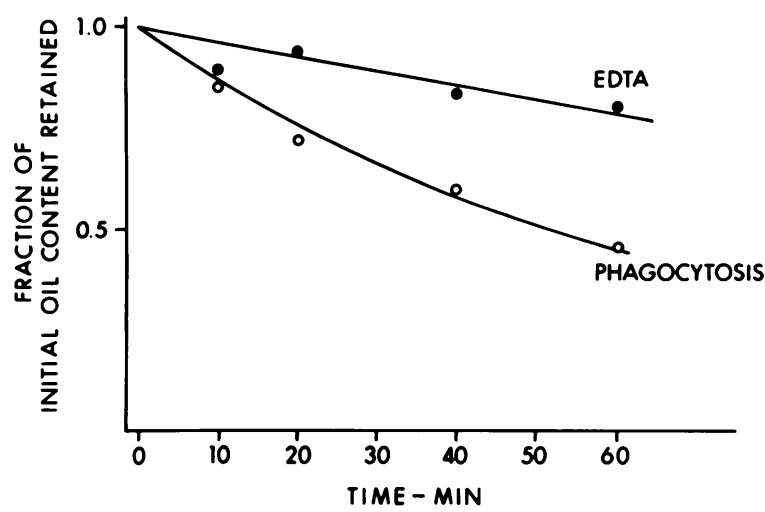

FIGURE 8 Fraction of perylene-labeled phagocytized oil remaining after incubation at $22^{\circ} \mathrm{C}$ in medium containing EDTA or ORO-labeled emulsion. Cells were initially loaded by phagocytosis of perylene-labeled oil for $10 \mathrm{~min}$ at $37^{\circ} \mathrm{C}$. The plots are an average of five experiments in which cell loss and lactate dehydrogenase excretion were negligible. In both cases loss of oil is evident, but the loss is clearly accelerated by phagocytosis. The difference between EDTA and phagocytosis incubations is significant at the $P<0.001$ level. ORO oil content rose continuously by phagocytosis in the release period, and at $40 \mathrm{~min}\left(22^{\circ} \mathrm{C}\right)$ was roughly equal to that attained in the initial $10 \mathrm{~min}$ ingestion $\left(37^{\circ} \mathrm{C}\right)$ of perylene-labeled oil.

discharge suggests that significant regions of recycled membrane are simply lost from the cell. In previous studies of the fate of membrane constituents during phagocytosis, we have shown in alveolar macrophages that membrane containing transport sites is not inserted from intracellular precursors during the period of endocytosis (10), and argued for a similar lack in PMN. This is not contradicted by the present experiments since exocytosis would not effect significant changes in membrane composition in the course of a short period of phagocytosis, but rather should become important during prolonged recovery.

By use of different labels for the bovine serum albumin-coated emulsion it is shown that phagocytosis and exocytosis can occur simultaneously. Moreover ingestion clearly accelerates the rate of exocytosis. Whether this is signaled by a volume change per se or some membrane event is not clear at this time. However, the phenomenon has several interesting implications. First, it is possible that cycling bacteria through ingestion and exocytosis could amplify the leukocyte's killing potential. Thus, the number of organisms killed might exceed the number present at any time within the cell. Second, feeding leukocytes an innocuous particle could force the exocytosis of toxic ones including perhaps obligate intracellular microorganisms that then would become susceptible to extracellular therapeutic agents. Realization of these possibilities must await description of the range of particles and phagocytes that display reversal. However, our studies with an inert nontoxic emulsion have made clear the 
existence of a rapid reversal process in mammalian neutrophils.

\section{ACKNOWLEDGMENT}

Supported by National Institutes of Health grants CA 15544 and GM 22621.

\section{REFERENCES}

1. Silverstein, S. C., R. M. Steinman, and Z. A. Cohn. 1977. Endocytosis. Ann. Rev. Biochem. 46: 669-722.

2. Stewart, J. R., and R. A. Weisman. 1972. Exocytosis of latex beads during the encystment of Acanthamoeba. J. Cell Biol. 52: 117-130.

3. Kaiser, H. K., and W. D. Wood, Jr. 1962. Studies on the pathogenesis of fever. IX. The production of endogenous pyrogen by polymorphonuclear leukocytes. J. Exp. Med. 115: 27-35.

4. Stossel, T. P., R. J. Mason, J. Hartwig, and M. Vaughan. 1972. Quantitative studies of phagocytosis by polymorphonuclear leukocytes. Use of paraffin oil emulsions to measure the initial rate of phagocytosis. J. Clin. Invest. 51: 615-624.

5. Magnusson, K-E., C. Dahlgren, O. Stendahl, and T. Sundquist. 1977. Characteristics of the phagocytic process assessed by Coulter counter. Acta Pathol. Microbiol. Scand. Sect. C. Immunol. 85: 215-221.

6. Hawkins, R. A., and R. D. Berlin. 1969. Purine transport in polymorphonuclear leukocytes. Biochim. Biophys. Acta. 173: 324-337.

7. Berlin, R. D., and J. P. Fera. 1977. Changes in membrane microviscosity associated with phagocytosis: effects of colchicine. Proc. Natl. Acad. Sci. U. S. A. 74: 10721076.

8. Stossel, T. P., J. D. Pollard, R. J. Mason, and M. Vaughan. 1971. Isolation and properties of phagocytic vesicles from polymorphonuclear leukocytes. J. Clin. Invest. 50: 1745- 1757 .

9. Steinman, R. M., S. E. Brodie, and Z. A. Cohn. 1976. Membrane flow during pinocytosis. A stereologic analysis. J. Cell Biol. 68: 665-687.

10. Tsan, M. F., and R. D. Berlin. 1971. Effect of phagocytosis on membrane transport of nonelectrolytes. J. Exp. Med. 134: 1016-1035. 